\title{
BCCN4
}

\section{INFLUENCE OF ENVIRONMENTAL DEGRADATION IN MECHANICAL AND MICROSTRUCTURAL PERFORMANCE IN POLYMERIC COMPOSITES INCREASED BY LICURI FIBERS}

\author{
Alexandre S. Moraes ${ }^{(1)}$, Ana C. R. da Conceição ${ }^{(2)}$, Pedro A. P. Almeida ${ }^{(1)}$, Helen F. \\ Sousa ${ }^{(1)}$, Olímpio B. C. V. Neto ${ }^{(1)}$, Mirtânia A. Leão ${ }^{(1)}$ \\ (1) IFBA - Federal Institute of Education Science and Technology of Bahia, Bahia, Brazil \\ (2) Department of Civil Engineering, Federal University of Bahia, Brazil
}

https://doi.org/10.21452/bccm4.2018.10.02

\begin{abstract}
The search for new composites that use natural fibers as reinforcement has driven the study of the vegetal fibers they are renewable, biodegradable, low cost and cause low environmental impact. Licuri fiber is obtained from the leaves of the Syagrus Coronata palm tree and possesses sufficient malleability to be woven. However, this type of material is subject to changes in mechanical behavior as a consequence of the natural degradation, mainly to those due to moisture absorption that can cause irreversible structural damage. In this sense, the present work sought to make an analysis of the influence of moisture on the mechanical performance of a unidirectional composite laminate of polyester matrix reinforced with licuri fibers. The composite laminates were manufactured by the by hand lay-up process. Water absorption, Uniaxial tensile and Three-point bending tests were perfomed according to ASTM D 570-98, ASTM D 3039-08 and ASTM D 790-07 standards, respectively. The results obtained on tests with composite in saturated state when compared to the tests with composite in the dry state (literature data) have shown that the polyester matrix composite reinforced with natural licuri fibers has its mechanical properties reduced by around $27 \%$ when exposed to moisture, as a confirmation of the hydrophilic nature of plant fibers.
\end{abstract}

Key words: Licuri fibers, Laminate composite, Mechanical properties, Moisture absorption.

\section{INTRODUCTION}

The use of composites reinforced with natural fibers has increased in the last decades, due to the perspective of energy saving by reducing the weight of the components, as well as the aspects related to the recovery of the raw materials and the reuse of the materials at the end of the product life cycle [1,2].

Thus, natural fiber reinforced polymer composites have received special attention due to the advantages of natural fibers when compared to synthetic fibers, since they are from 
renewable sources, have low density and low cost, are non-toxic, can be incinerated, biodegradable and mainly because they are considered sustainable [3,4].

The automobile industry has been developing research on the greater use of natural fibers in place of synthetic inputs. These fibers are already used in the manufacture of automotive parts, providing quality and well-being to the user, such as filling seats and headrests, side and door panels, instrument panel, air channel, roof coating, carton wheels and others. Among the fibers used are: sugarcane bagasse, sisal, jute, curauá and coconut fiber [5,6].

The vegetable fibers can undergo degradation due to biological agents, acidic and alkaline media, moisture absorption, ultraviolet radiation and temperature.

In the case of aging by moisture absorption the fibers reinforced by vegetable fibers, the water molecules absorbed by these fibers due to their hydrophilic nature act as plasticizers interfering in the fibers, the matrix and the interface simultaneously. Displacement at the fiber/resin interface may occur due to the development of osmotic pressure pockets on the fiber surface due to the leaching of water soluble substances from the fiber surface. In this way, the degradation of the composite occurs not only by the degradation of the individual constituents, matrix and fiber, but also due to the loss of the interaction between them [7].

The licuri fiber, originating from the Syagrus Coronata (Martius) Beccari palm, can be found in the vegetation of the Brazilian Caatinga. Endemic to South America and widely present in the states of Bahia and Minas Gerais [8], the licuri palm has its fruit widely used in the food and cosmetics sectors, while its fiber has more restricted application for craft purposes. More recently, the licuri fiber was studied as an alternative proposal for the reinforcement of polymer composites [9].

\section{MATERIAL AND METHODS}

The study material was a laminate composite with two layers of licuri unidirectional manufactured in manual loom.

The licuri fibers were passed on rolling rollers and treated with the solvent Hexano PA for a minimum period of 24 hours for removal of the natural wax fibers, in order to improve the process of impregnating the polyester resin.

The hand lay-up process was used to manufacture the composites laminates. The orthophthalic polyester resin (Novapol L120) as matrix. As a catalyst for curing the resin at room temperature, the methyl ethyl ketone solvent (MEKP) was used in the proportion of $1 \%$ of the resin volume, the curing process being at room temperature $\left(25^{\circ} \mathrm{C}\right)$. The weight obtained in the licuri tissue used in this work was $418.27 \mathrm{~g} / \mathrm{m}^{2}$.

The composite laminate (LCL) in its final design had the following dimensions (400x500x 4) mm, which corresponds to width, length and thickness respectively.

\subsection{Water Absorption Test}

To study the behaviour of water absorption of LCL laminates, water absorption test were carried out according ASTM D570-98. Composites samples were immersed in distilled water maintained at room temperature $\left(25^{\circ} \mathrm{C}\right)$ and at a time interval 24 hours, the samples were removed from water, dried and weighed. The weight measurement was taken periodicall for 336 hours which was after saturation in all the composites had been noticed.

Lastly, the weighings started to have intervals of two weeks, that is, of 14 days, until the difference of the increase of mass, and relation to the previous weighing was less than $1 \%$.

\subsection{Uniaxial tensile test}

The uniaxial tensile test was performed according to ASTM D 3039-08 standard. Tests were performed for eight specimens fractured and five values recorded (required by standard) of the valid tests considdered. Uniaxial tensile test was conducted in the Universal 
Mechanical Testing Machine (DL $300 \mathrm{kN}$ EMIC), with a loading speed of $1.0 \mathrm{~mm} / \mathrm{min}$ and the average ambient temperature during the $(25 \pm 2){ }^{\circ} \mathrm{C}$. The dimensions of LCL laminate specimens were $(250 \times 25 \times 4) \mathrm{mm}$, respectively for length, width and thickness. The dimensions have tolerances of $\pm 1 \%$. The gauge length (span/greyhound) of all test specimens was $127 \mathrm{~mm}$.

\subsection{Three-point bending test}

The three-point bending test after moisture absorption test was performed according to ASTM D 790-10 standard, being obtained for laminates proposed, the flexural strenght and flexural elastic modulus. The three-point bending test using a Universal Mechanical Testing Machine (DL $300 \mathrm{kN}$ EMIC), and the loading speed of $2.0 \mathrm{~mm} / \mathrm{min}$ and dimensions of the LCL laminate specimens were $(100 \times 13 \times 4) \mathrm{mm}$ and span of $80 \mathrm{~mm}$. The dimensions correspond to lenght, width, and thickness, respectively. The average ambient temperature during the test was $(25 \pm 2){ }^{\circ} \mathrm{C}$.

\subsection{Analysis of fractures.}

In order to analyze the real influence of the moisture degradation will be performed a qualitative analysis of mechanical fracture through of microscopic analysis. Optical microscopy was used the microscope Olimpus MG. For scanning electron microscopy (SEM), the microscope TECSAN, model Vega 3 LMU it was used.

\section{RESULTS}

\subsection{Morphological evaluation}

Figure 1 (a) and (b) shows the chromatic variation (photoxidation) of the surface of the specimens, before and after the moisture absorption test respectively, which is usually a first indication of the loss of the mechanical integrity of the material.
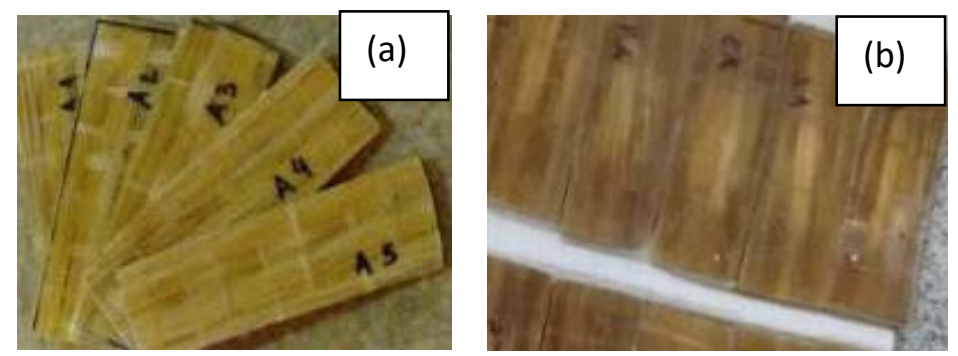

Figure 1: Chromatic variation of specimens surface. (a) before the moisture absorption test (dry); b) After the moisture absorption test.

\subsection{Moisture absorption test}

The mean values for mass gain of the composite due to the moisture absorption is shown graphically (Figure 2). The onset of saturation occurred at the 15th week of the test and the saturation condition at the 19th week was reached, according to ASTM D570-98 for the water absorption test for polymers. The material reached a mean mass increment of $4.97 \%$ after 336 hours of the moisture (saturation) test. According to previous studies, composites reinforced with only natural fibers generally absorb a higher percentage than those reinforced with synthetic fibers and hybrid composites. 


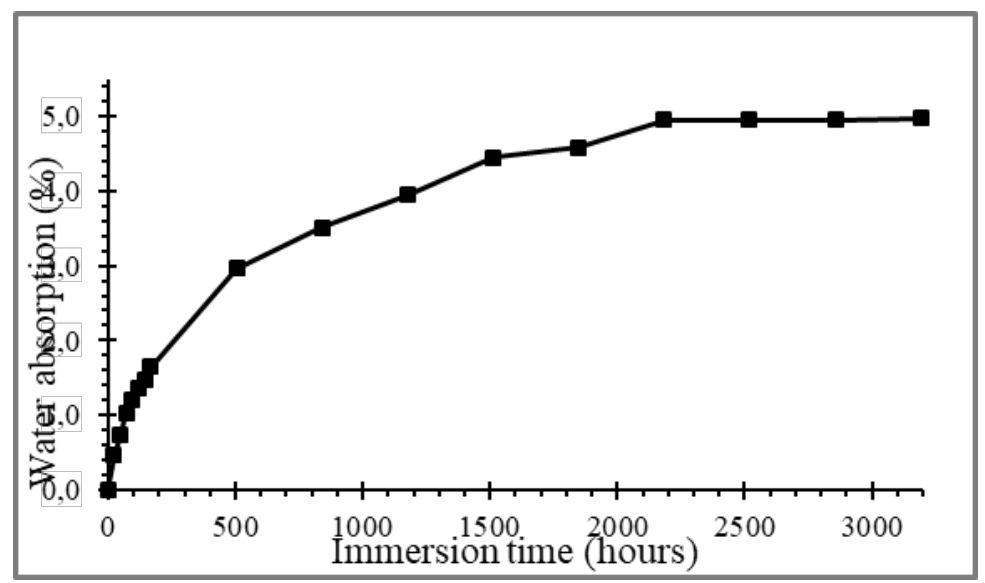

Figure 2: Water absorption versus Immersion time graph.

\subsection{Mechanical Properties - uniaxial tensile}

Mechanical behavior related to the uniaxial tensile test of LCL laminate are presented from the strees-strain diagram see Figure 3. LCL laminate has a linealy elastic behavior between the tension and the deform beginning from damage (approximately $40 \%$ of tensile strengt) to fracture.

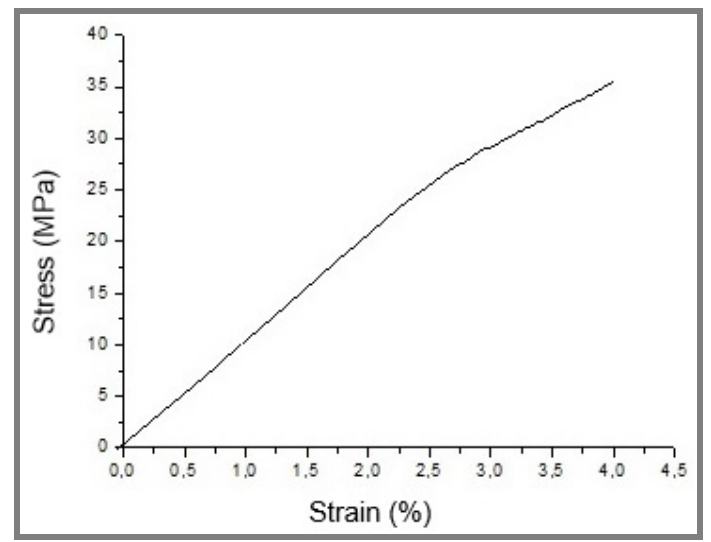

Figure 3: Stress x strain diagram - uniaxial tensile test.

Table 1 show the result of the mechanical properties (average values) and standard deviation obtained for uniaxial tensile test of LCL laminate. With respect to the modulus of elasticity value, it was calculated before the initial damage was started, in order to avoid the influence on the stiffness of the material.

Table 1: Mechanical properties - laminate LCL - uniaxial tensile.

\begin{tabular}{lc}
\hline Mechanical properties & Average \\
\hline Tensile Strength (MPa) & $31,39 \pm 4,3$ \\
Elastic Modulus (GPa) & $0,95 \pm 0,1$ \\
Elongation (\%) & $3,39 \pm 0,2$ \\
\hline
\end{tabular}

\subsection{Mechanical Properties of LCL Laminate - Three-Point BendingTest}

Figure 4 shows the performance of the mechanical properties obtained from three-point bending test for both laminates, from the stress-flexural strain diagram. The LCL laminate has a linearly elastic behavior until the final fracture of the material. 


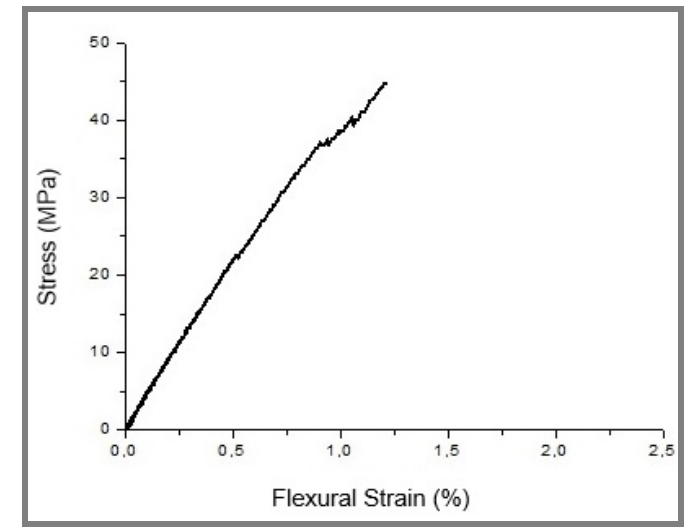

Figure 4 : Stress x Flexural Strain - three-point bending.

Table 3 it is possible to observe the synthesis of results of the mechanical properties (average values) determined at the three-point bending test as well as the values of the respective standard deviations.

Table 3: Mechanical properties - laminate LCL - Three-point bending.

\begin{tabular}{lc}
\hline Mechanical properties & Average \\
\hline Flexural strength (MPa) & $41,15 \pm 1,03$ \\
Flexural modulus (GPa) & $3,94 \pm 0,33$ \\
Flexural strain (\%) & $1,31 \pm 0,04$ \\
\hline
\end{tabular}

\subsection{Global Comparative diagram - Influence of moisture degradation}

Figure 5 show a global view of uniaxial tensile test behavior for dry LCL laminate and wet LCL laminate. The wet LCL laminate exhibited a loss of tensile strength and a gain in elongation.

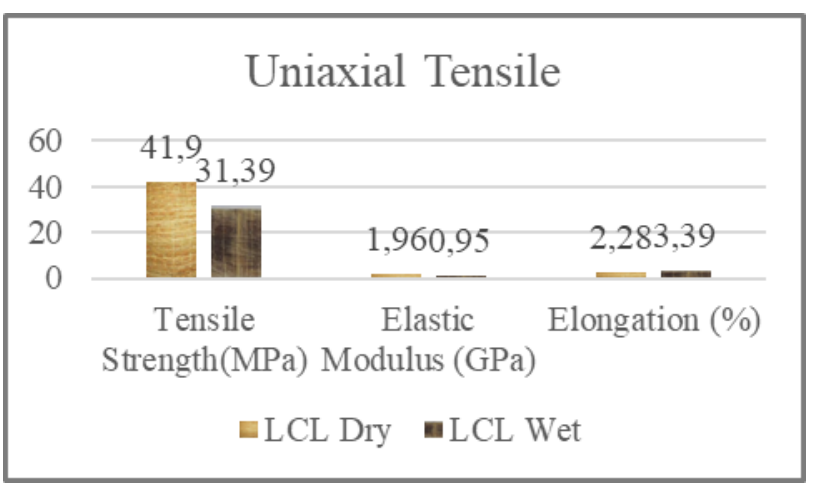

Figure 5: Global comparation - uniaxial tensile test.

Figure 6 show a global view of three-point bending test behavior for dry LCL laminate and wet LCL laminate. In relation to the moisture degradation process, the wet LCL laminate exhibited a loss of flexural strength and a gain in flexural modulus. 


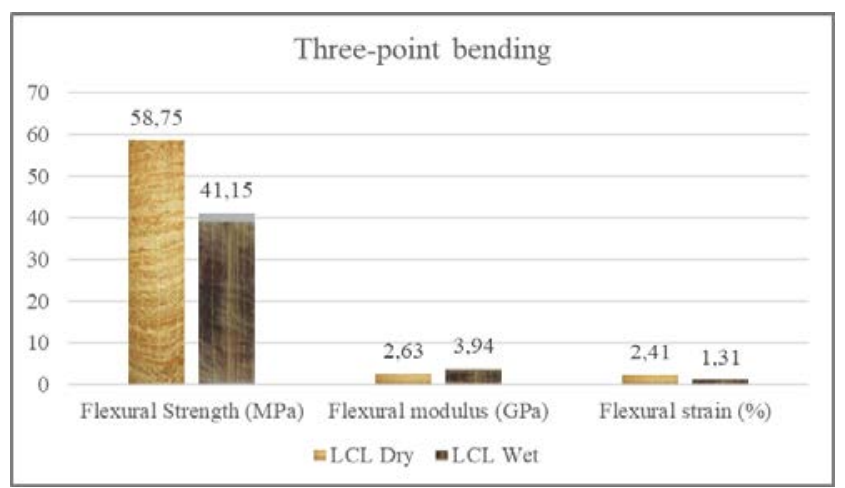

Figure 6: Global comparation - three-point bending test.

\subsection{Fracture Analysis - uniaxial tensile test}

The analysis of optical microscopy occurs in the fractured region (along the specimens thickness) of the LCL laminate, as shown in Figure 7. It is possible to observe cohesive fracture in the fibers, as well as, adhesive fracture in the fiber/matrix interface.

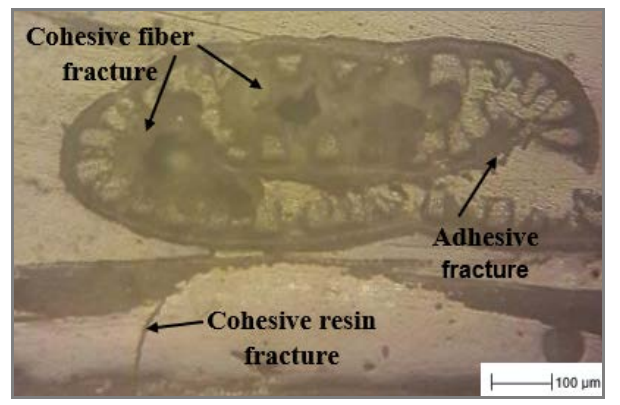

Figure 7: Fracture characteristics - LCL laminate.

By scanning electron microscopy (SEM), as shown in Figure 8, it is observed in the fracture region of the LCL laminate, the presence of cohesive fracture in the licuri fiber this type of damage tends to break the fiber longitudinally.

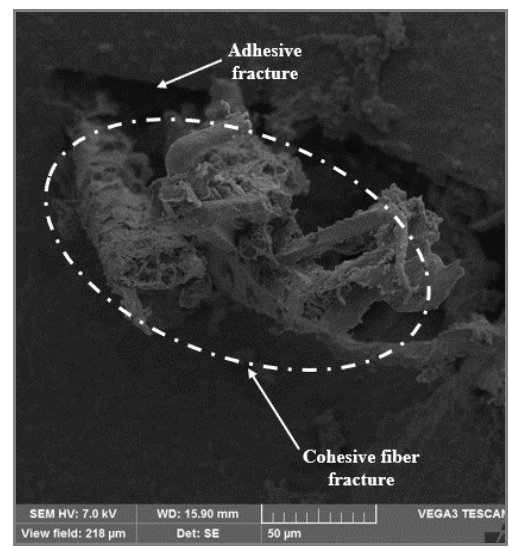

Figure 8: Fracture characteristics - LCL laminate.

\subsection{Fracture Analysis - three-point bending test}

Analyzing the optical microscopy of the transverse face of the sample, figure 9 . It is possible to observe the presence of cohesive fracture in the matrix, where the propagation of the microcracks causes a demolding of the fiber/matrix (adhesive fracture). 


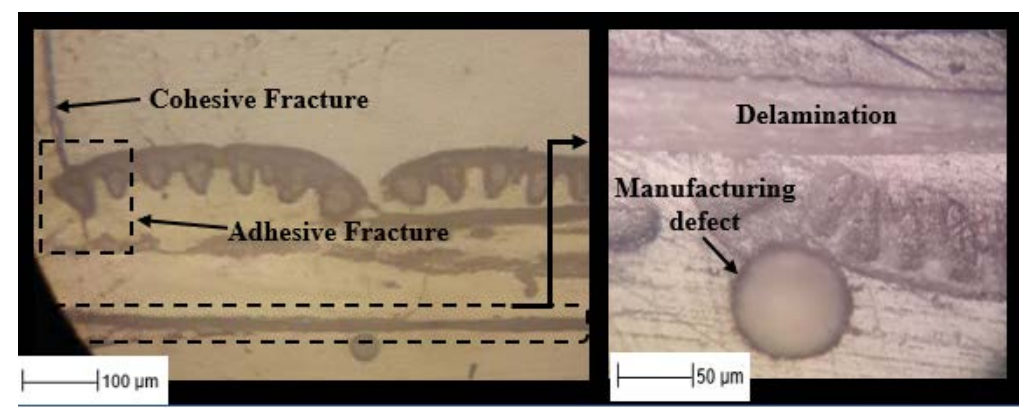

Figure 9: Fracture characteristics - LCL laminate.

In Figure 10 microscopy by SEM can be observed to delaminate, in addition to the formation of grooves in the matrix.

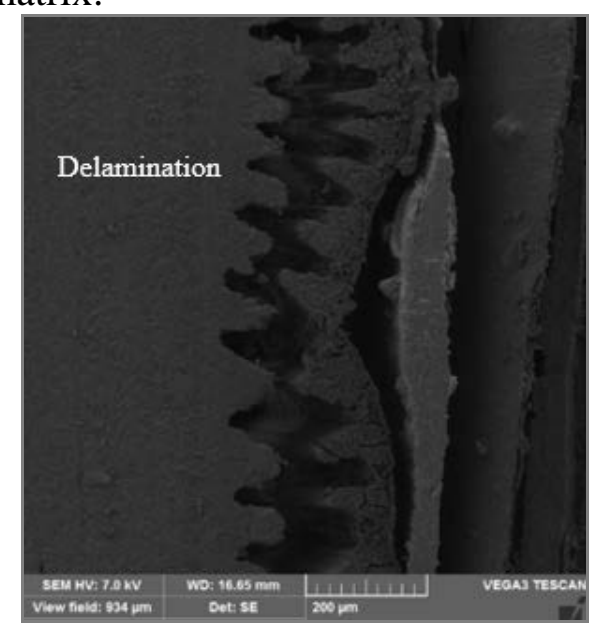

Figure 10: Fracture characteristics - LCL laminate..

\section{CONCLUSIONS}

- The moisture interferes in the fiber matrix adhesion and weakens the matrix, affirming the hydrophilic nature of the fibers.

- With respect to the last tensile strength property, the LCL laminate in the dry state presented superiority with respect to the LCL laminate in the saturated wet state, presenting a traction loss of approximately $25.08 \%$, while for the Longitudinal Elasticity Modulus LCL laminate in the saturated wet state was superior, resulting in a gain of $48.68 \%$.

- With respect to the property of Ultimate Flexural Strength and Modulus of Flexural Elasticity, the LCL laminate in the wet state presented reduction of approximately $29.96 \%$ and a gain of $49.81 \%$ respectively.

- Regarding the fractures of the LCL laminate after being submitted to the uniaxial tensile test, the fracture occurred perpendicular to the application of the load and within the useful area of the specimen.

- For the three-point bending test, it is observed that the fractures in the LCL laminate occurred on both the traction face.

\section{REFERENCES}

[1] Alves, C.; Ferrão, P. M. C.; Silva, A. J.; Reis, L. G.; Freitas, M.; Rodrigues, L. B.; Alves, D. E. Ecodesign of automotive components making use of natural jute fiber composites. Journal of Cleaner Production, v.18, p.313-327, 2010. 
[2] Cerqueira E.F.; Baptista C. A. R. P.; Mulinari D. R. Mechanical behaviour of polyproplene reinforced sugarcane bagasse fibers composites. ICM11 (ScienceDirect), v.10, 2046-2051, 2011.

[3] Guimarães, J. L.; Frollini E.; Da Silva, C. G.; Wypych, F.; Satyanarayana, K. G. Characterization of banana, sugarcane bagasse and sponge gourd fibers of Brazil. Industrial Crops Production, v.30, p.407-415, 2009.

[4] Zah, R.; Hischier, R.; Leão, A. L.; Braun, I. Curauá fibers in the automobile industry - a sustainability assessment. Journal of Clear Production, v.15, p.1032-1040, 2007.

[5] Ramires, E. C.; Megiatto Junior, J. D.; Gardrat, C.; Castellan, A.; Frollini, E. Biobased composites from glyoxal-phenolic resins and sisal fibers. Bioresource Technology, v. 101, p. 1998- 2006, 2010.

[6] Ibrahim, M. M.; Dufresne, A.; El-Zawawy, W. K.; Agblevor, F. A. Banana fibers and microfibrils as lignocellulosic reinforcements in polymer composites. Carbohydrate Polymers, v.81, p.811-819, 2010.

[7] Leão, M. A.; Tinô S. R. L.; Aquino E. M. F. Accelerated environmental aging effects in structural integrity of licuri fiber reinforced plastics. Journal of Reinforced Plastics and Composites, v.34(5) 351-363, 2015.

[8] Rufino, M. U. L.; Costa, J. T. M.; Silva, V. A.; Andrade, L. H. C. Conhecimento e uso do ouricuri (Sagrus coronata) e do babaçu (orbignya phalerata) em Buíque, PE, Brasil. Acta bot. bras., v. 22, n. 4, p. 1141-1149, 2008.

[9] Leão, M. A. et al.; Licuri fibers: alternative reinforcement to polymeric composites. Journal of Reinforced Plastics and Composites, v. 30(6), p. 516-523, 2011. 